\title{
USE OF TRIOLEIN-SEMIPERMEABLE MEMBRANE DEVICES TO ASSESS THE BIOCONCENTRATION AND SEDIMENT SORPTION OF HYDROPHOBIC ORGANIC CONTAMINANTS IN THE HUAIHE RIVER, CHINA
}

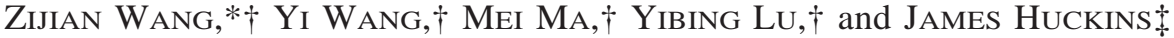 \\ $\dagger$ State Key Laboratory of Environmental Aquatic Chemistry, Research Center for Eco-Environmental Sciences, P.O. Box 2871, \\ Beijing 100085, China \\ $\ddagger$ Columbia Environmental Research Center, U.S. Geological Survey, 4200 New Haven Road, Columbia, Missouri 65201, USA
}

(Received 11 February 2001; Accepted 24 April 2002)

\begin{abstract}
Triolein-containing semipermeable membrane devices (triolein-SPMD) were deployed $1 \mathrm{~m}$ above the sediments at two sampling sites in the Huaihe River, China, for a period of $28 \mathrm{~d}$. Sediment and fish samples were simultaneously collected from the same sampling sites. Concentrations of substituted benzenes, selected pesticides, polycyclic aromatic hydrocarbon (PAH), and polychlorinated biphenyls (PCBs) were measured in triolein-SPMDs, sediments, and fishes. The concentrations of these hydrophobic organic contaminants (HOCs) in fish and in sediment organic carbon were correlated with HOCs accumulation in triolein-SPMDs. Our results showed reasonably good correlations between the log concentrations of contaminants in fish lipid and in triolein-SPMDs. Good correlations were also found between the log concentrations of contaminants in sediment organic carbon and in trioleinSPMDs (except for PAHs). The results were discussed in terms of the partitioning of hydrophobic organic contaminants among different compartments in the aquatic environment and the suitability of using triolein-SPMDs to predict bioconcentration factor $(\mathrm{BCF})$ and sediment-water partitioning coefficient $\left(K_{\mathrm{oc}}\right)$.
\end{abstract}
Keywords-Hydrophobic organic contaminants
Partitioning
Bioconcentration
Sediment sorption
Triolein-semipermeable membrane devices

\section{INTRODUCTION}

The aquatic environment is a multimedia system consisting of water, suspended particulates, dissolved organic carbon, benthic sediment, and aquatic organisms. The levels of dissolved hydrophobic organic contaminants (HOCs) are of great importance because aqueous dissolution is generally necessary for intermedia transfer of pollutants. Typically, sediment acts as a reservoir for HOCs, but they also exchange chemical residues with the aqueous phase. Most aquatic organisms accumulate chemicals by ventilation of water or by skin absorption (bioconcentration includes both routes of uptake), through the food web, and/or through direct ingestion of sediment.

The partitioning of HOCs between water and sediment $[1,2]$ and between water and aquatic organisms [3,4] can be predicted by their octanol-water partition coefficients $\left(K_{\mathrm{ow}} \mathrm{s}\right)$. However, applications of these models to predict environmental concentrations often fail to fit directly measured values. Uhle et al. [5] has suggested that this is due to uncertainties such as the variability of contaminant bioavailability with concentrations of natural organic matter in waters.

Assessment of polluted field sites requires knowledge of sediment-water partition coefficients $\left(K_{\mathrm{p}}\right.$ or the organic carbon-normalized $K_{\mathrm{oc}}$ ) and bioconcentration or bioaccumulation factors (BCF or BAF)[6]. Typically, the availability of appropriate values for $K_{\mathrm{oc}} \mathrm{s}$ and BCFs (or BAFs) in the literature is limited to a few types of chemicals, sediments, and species. Data from fish used in contaminant assessments in different geographical areas are often difficult to compare because of differences in species and their tolerances. In addition, the use

* To whom correspondence may be addressed (wangzj@mail.rcees.ac.cn). of known $\log \mathrm{BAF}\left(\right.$ or BCF) $\sim \log K_{\mathrm{ow}}$ or $\log K_{\mathrm{oc}} \sim \log K_{\mathrm{ow}}$ relationships to estimate contaminant body burdens in endemic species or to evaluate sediment quality is limited by the difficulty of measuring bioavailable or free concentration of a contaminant in the aqueous phase because these relationships are largely affected by the presence of natural organic carbons.

Efforts have been made to address the issues of the availability of appropriate test species and organism mobility by using caged fish [7]. However, caging selected species of fish at sites where water or sediment is sampled is limited by the availability of test fish with very low levels of target contaminants, environmental stressor effects on bioaccumulation and survival, convenience, and the relatively high cost.

Triolein-containing semipermeable membrane devices (triolein-SPMDs) have been proposed as an alternative or a complement to traditional bioaccumulation studies for assessing the levels of bioavailable hydrophobic organic contaminants in aquatic environments [7-10]. In theory, contaminants are passively accumulated in the triolein-SPMDs in a manner similar to their bioconcentration in fish lipid and partitioning into sediment organic carbon [8]. Therefore, triolein-SPMDs may serve as an acceptable surrogate for caged fish exposures to HOCs $\left(\log K_{\text {ow }} \leq 6.0\right)$ without being subject to most of the limitations listed earlier.

The sampling process of triolein-SPMD mimics the passive transfer of organic contaminants through the respiratory lamellae of fish. It has been used mainly to monitor HOCs in water and air [11-14]. However, the potential utility of the similarity in the passive concentration of dissolved HOCs by SPMDs, fishes, and sediments has not been adequately explored. Furthermore, when compared to classic environmental assessment methods, SPMD technology appears to be a powerful tool for modeling the environmental behavior and fate 
of contaminants in aquatic multimedia systems. Advantages over existing methods include simplicity, convenience, reproducibility, and the relative insensitivity of triolein-SPMD sampling rates to differences in water quality.

The Huaihe River is an important natural water body that flows through four provinces in central China. Unfortunately, it is one of the most polluted rivers in China. In this study, concentrations of HOCs in water, feral fish, and sediment were measured at two sites along the Huaihe River. Levels of HOCs of concern were compared to those found in exposed trioleinSPMDs. The results are discussed in terms of the partitioning of organic contaminants among water, sediment organic carbon, biota, and triolein-SPMDs.

\section{MATERIALS AND METHODS}

\section{Assembly of triolein-SPMDs}

The SPMD technology is the subject of U.S. Patents $5,098,573$ and 5,395,426. Lay-flat low-density polyethylene (pure product without additives; Beijing Plastics, Beijing, China) tubing used for SPMDs was $2.5 \mathrm{~cm}$ in width, $22.8 \mathrm{~cm}$ in length, and $85 \mu \mathrm{m}$ thick. It was soaked in cyclohexane for 24 $\mathrm{h}$ to remove trace contaminants and dried with ultrapure nitrogen. The ratio of the mass of tubing to the volume of extraction solvent was $0.01 \mathrm{~g} / \mathrm{ml}$. Then $250 \mu \mathrm{l}$ of triolein $(99 \%$ pure; Sigma Chemical, St. Louis, MO, USA) were coated onto the inner part of the tubing before the ends were sealed with a commercial plastic sealer [9]. After assembly, the total mass of a SPMD was $0.85 \mathrm{~g}$. These devices met the specifications of a standard SPMD, as described by Huckins et al. [15]. Each triolein-SPMD was enclosed in the aluminum foil, which was sealed in a hexane-rinsed metal container and stored at $-20^{\circ} \mathrm{C}$. For deployment, triolein-SPMDs were fixed to solvent-cleaned polyvinylchloride plastic mesh cages $(5 \times 3 \times 25 \mathrm{~cm}$; Haidian Plastics, Beijing, China).

\section{Sampling}

Two sites along the Huaihe River were sampled: The sampling site at Xinyang city was upstream of Huahe River and less affected by pollution discharge, and the sampling site at Huainan city was in the middle of the river. The sampling was carried out in spring, and water temperature ranged from 12.5 to $14.5^{\circ} \mathrm{C}$. The flow rates were about $1 \mathrm{~m} / \mathrm{s}$ and were relatively constant at both sampling sites. The distance between the two sites was approximately $400 \mathrm{~km}$, and the time required for a volume of water to move by the two test sites was estimated to be 4 to $5 \mathrm{~d}$.

Fish and benthic sediment were sampled at each site at the time of SPMD recovery. Duplicate sediment samples were excised with a stainless-steel sampler (0-20 cm depth). Each sediment sample was well mixed to ensure homogeneity and subsampled. Fish were caught several meters above the sediment, and only 15- to 20-cm-long fish (Cyprinus carpio) were selected for analysis. After returning to the laboratory, fish were separated into muscle and other tissues, and a composite sample with muscle tissue from three fish was analyzed and reported. At each sampling site, four SPMDs were removed from their containers and attached to the polyvinylchloride plastic mesh cage described earlier. The cage was kept $1 \mathrm{~m}$ above the sediment by tethering to a heavy weight and a float. Triolein-SPMD field blanks were exposed to site air at the time of deployments but sealed back in the same containers and stored frozen in the laboratory. All field-deployed SPMDs were exposed for a period of $28 \mathrm{~d}$ before they were recovered.
The organic matter content of sediments was measured gravimetrically. A portion of each sample $(\sim 10 \mathrm{~g})$ was first dried at $105^{\circ} \mathrm{C}$ for $5 \mathrm{~h}$ to obtain water content and then heated at $600^{\circ} \mathrm{C}$ for $12 \mathrm{~h}$ to derive the organic carbon content. To measure lipid content, about $10 \mathrm{~g}$ of fish muscle were homogenized with $10 \mathrm{~g}$ anhydrous sodium sulfate. Then the dry 20-g muscle-sodium sulfate mixture was Soxhlet extracted (Millville, NJ, USA) with $60 \mathrm{ml}$ organic solvent (cyclohexane: acetone:petroleum ether $[1: 1: 1, \mathrm{v} / \mathrm{v} / \mathrm{v}])$ at $70^{\circ} \mathrm{C}$ for $12 \mathrm{~h}$. After evaporation of solvent from extracts, lipid content was measured gravimetrically. In this work, we normalized the concentrations of target contaminants to the organic carbon content in sediments and the lipid content in fish and triolein content in SPMD. Note that the normalization procedure is not valid unless the matrices of concern have reached equilibrium concentrations. The reasons for the assumption of residue equilibrium in exposed SPMDs are discussed in the Results and Discussion section.

\section{Preparation of samples}

After removal of triolein-SPMDs from their deployment cages, all exterior membrane surfaces were cleaned with contaminant-free, dry pledgets; rinsed with distilled water for 30 $\mathrm{s}$; and finally cleaned with cotton pledgets containing a small amount of hexane. After cleaning, each device was dialyzed for $48 \mathrm{~h}$ in $100 \mathrm{ml}$ of high-purity cyclohexane (cyclohexane: triolein [100:1, v/v]). Fish and sediment samples were Soxhlet extracted as described for analysis of lipid content, and the volume of each extract was reduced to about $10 \mathrm{ml}$ using a vacuum rotary evaporator (Buchi Rotavapor, Flawil, Switzerland) and to about $1 \mathrm{ml}$ using a gentle stream of nitrogen (GR grade, Beijing Chemical). All sample extracts were cleaned up by percolation through tandem columns $(150 \times 10 \mathrm{~mm})$; each contained a bottom layer of $4 \mathrm{~g}$ deactivated silica gel (60-80 mesh, dried for $5 \mathrm{~h}$ at $135^{\circ} \mathrm{C}$, and deactivated with $5 \%$ distilled water for $30 \mathrm{~min}$ ) and a top layer of $4 \mathrm{~g}$ of anhydrous sodium sulfate (dried for $12 \mathrm{~h}$ at $550^{\circ} \mathrm{C}$ ). The columns were rinsed with $10 \mathrm{ml}$ hexane before sample loading. The samples were applied and eluted with $40 \mathrm{ml}$ hexane. For sediment samples, the extracts were further treated with acid-activated copper wool to remove sulfur. After purification, the eluates were reduced to $1 \mathrm{ml}$ using a gentle stream of nitrogen.

\section{Analysis of target contaminants}

Twelve substituted benzene, three pesticides, 16 PAHs, and 57 PCB congeners (mostly lower chlorinated PCBs [International Union of Pure and Applied Chemistry no. 5-101]) were analyzed. A Hewlett-Packard HP5890II capillary (Avondale, PA, USA) gas chromatography/mass spectrometry (GC-MS) system with a HP5971A mass selective detector and an HP-5 column $(60 \mathrm{~m} \times 0.32 \mathrm{~mm}$ i.d., $0.25 \mu \mathrm{m}$ film thickness $)$ with helium carrier gas was used for the analysis of substituted benzenes and pesticides. The column temperature was initially held at $50^{\circ} \mathrm{C}$ for $1 \mathrm{~min}$, then it was increased at $6^{\circ} \mathrm{C} / \mathrm{min}$ to $250^{\circ} \mathrm{C}$ and held for $30 \mathrm{~min}$. A mixture of standard chemicals was used to quantify substituted benzenes and pesticides.

Sample analysis for PCBs was also performed by GC-MS (same instrument as described previously) with helium as the carrier gas. However, two identical HP-5 columns $(30 \mathrm{~m} \times$ $0.25 \mathrm{~mm}$ i.d., $0.25 \mu \mathrm{m}$ film thickness) were connected in series for resolution of PCB congeners. To avoid any interference due to polyethylene waxes and lipids, single ion monitoring (SIM) was used. In this mode, the detection limit for PCBs 
Table 1. Normalized concentrations of substituted benzenes and pesticides in fish, sediment, and semipermeable membrane devices (SPMD)

\begin{tabular}{|c|c|c|c|c|c|c|}
\hline \multirow[b]{2}{*}{ Compounds } & \multicolumn{2}{|c|}{$\begin{array}{c}\text { Fish } \\
\text { (mg/kg lipid) }\end{array}$} & \multicolumn{2}{|c|}{$\begin{array}{c}\text { Sediment } \\
\text { (mg/kg organic carbon) }\end{array}$} & \multicolumn{2}{|c|}{$\begin{array}{c}\text { SPMD } \\
(\mathrm{mg} / \mathrm{kg} \text { triolein })\end{array}$} \\
\hline & Xinyanga & Huainan $^{a}$ & Xinyang & Huainan & Xinyang & Huainan \\
\hline Toluene & 3.1 & 3.6 & $3.9 \pm 0.6$ & $4.9 \pm 4.2$ & $4.2 \pm 0.7$ & $7.2 \pm 0.2$ \\
\hline p-Xylene & 1.9 & 2.3 & $5.6 \pm 1.1$ & $1.6 \pm 2.7$ & $4.4 \pm 0.5$ & $4.1 \pm 1.5$ \\
\hline$o$-Xylene & 9.4 & 13.3 & $16 \pm 1$ & $11 \pm 3.0$ & $16 \pm 2$ & $14 \pm 1$ \\
\hline Aniline & 5.5 & 7.9 & $11 \pm 0.5$ & $8.9 \pm 1.0$ & $13 \pm 1$ & $14 \pm 1$ \\
\hline 2-Chlorophenol & 3.5 & $\mathrm{ND}^{\mathrm{b}}$ & $6.9 \pm 1.0$ & $4.7 \pm 0.5$ & $8.0 \pm 0.1$ & $8.0 \pm 0.2$ \\
\hline Nitrobenzene & 3.7 & 5.6 & $7.2 \pm 0.3$ & $4.9 \pm 0.6$ & $8.3 \pm 0.2$ & $8.3 \pm 0.1$ \\
\hline 2,4-Dichlorophenol & 4.3 & 6.6 & $8.0 \pm 0.6$ & $6.7 \pm 1.2$ & ND & $9.9 \pm 0.1$ \\
\hline 2,3-Dichlorophenol & 4.3 & 6.6 & $8.0 \pm 0.7$ & $6.7 \pm 3.0$ & ND & $9.9 \pm 0.1$ \\
\hline 2,4,6-Trichlorophenol & 49.8 & 1496 & $543 \pm 140$ & $2,858 \pm 1,431$ & ND & $1,334 \pm 100$ \\
\hline 2,6-Dinitrobenzene & 8.6 & 15.1 & $13 \pm 0.5$ & $8.6 \pm 0.8$ & $17 \pm 1$ & $15 \pm 0.3$ \\
\hline 2,4-Dinitrobenzene & 10.6 & 14.8 & $16 \pm 1$ & $12 \pm 1$ & $22.6 \pm 0.6$ & $22 \pm 2$ \\
\hline Hexachlorobenzene & 7.8 & ND & $36 \pm 2$ & $30 \pm 18$ & $13 \pm 5$ & $28 \pm 14$ \\
\hline Atrazine & 123 & 182 & $267 \pm 5$ & $183 \pm 4$ & $307 \pm 1$ & $309 \pm 2.5$ \\
\hline Acetochlor & 3.3 & 5.1 & $6.6 \pm 0.3$ & $4.4 \pm 0.5$ & $7.6 \pm 0.1$ & $7.6 \pm 0.1$ \\
\hline
\end{tabular}

${ }^{\text {a }}$ China.

${ }^{\mathrm{b}} \mathrm{ND}=$ did not exceed detection limit.

was $0.1 \mathrm{pg}$. The temperature program used for GC-MS analysis was identical to that used for substituted benzenes and pesticides. Both Clophen A50 and Arochlor 1242 (Supelco, Bellefonte, PA, USA) were used to quantify the congeners.

Sample analysis for the 16 PAHs was performed on a Shimadzu model LC-10AD (Columbia, MD, USA) high-performance liquid chromatograph (HPLC) using a Zorbax C18 column (Micro-Tech Scientific, Sunnyvale, CA, USA) $(250 \times 4.6$ $\mathrm{mm})$. The HPLC was equipped with a SPD-M10A ultraviolet (UV) detector (Shimadzu). Instrumental conditions were as follows: wavelength, $254 \mathrm{~nm}$; flow rate, $1 \mathrm{ml} / \mathrm{min}$; and mobile phase, acetonitrile/water (70:30, v/v). Under the described conditions, benzo $(\alpha)$ anthracene and chrysene were not separated. A PAH mixture (U.S. Environmental Protection Agency's PAH mix, Supelco) was used to quantify the PAHs.

\section{Quality control}

Three SPMD field blanks accompanied SPMDs during transport, deployment, and retrieval. Processing of these blanks followed the same analytical procedures as those used for SPMDs deployed in the field. No PCB congeners or PAHs were detectable in SPMD blanks, but two measurable peaks corresponded to the retention times of toluene and nitrobenzene. However, their peak areas were much smaller (less than $1 \%$ ) than those in exposed SPMDs. A freshly prepared SPMD blank and a reagent blank (100 $\mathrm{ml}$ of organic solvent) were also taken through the entire cleanup and analytical procedure. No interferences or target compounds were found in these blanks. In addition, no detectable levels of PCBs and PAHs were found in the procedural blanks for sediment and fish samples.

In previous work, the recoveries for moderately hydrophobic chlorophenols and weakly hydrophobic nitroaromatics fell within a range of 63 to $75 \%$ with coefficient of variation ([CV] $<11 \%)$ for SPMDs and 57 to $71 \%(\mathrm{CV}<16 \%)$ for goldfish $[16,17]$. The same methods were used in this study but for different analytes. The recoveries of established analytical procedure for sediment and fish samples were in the range of 61 to $102 \%$ for benzenes, PCBs, and PAHs. We did not test for the recovery of the target compounds in field-deployed SPMD, but the procedural recovery was $>90 \%$ for dialytic and $>80 \%$ for cleanup, based on spikes of Clophen A50 (Bayer, LeVerkusen, Germany).

\section{RESULTS AND DISCUSSION}

Previous work [8] has pointed out that it is often inappropriate to lipid normalize biota and SPMD residue concentrations for comparisons of their relative levels. A key assumption of the lipid or carbon normalization process is that all target compounds in normalized matrices have achieved equilibrium with ambient water [8]. Clearly, this is not the case for SPMDs when target compounds have high $K_{\text {ow }}$ s $\left(\log K_{\text {ow }}>6\right)$, exposure waters are quiescent, temperatures are relatively low, and exposure times are $<30 \mathrm{~d}$. However, in this study, the high flow turbulence of exposure waters and the relatively low $K_{\text {ow }}$ s of the majority of the target contaminants suggest that the assumption of the attainment of $90 \%$ of equilibrium concentrations in the SPMDs is valid in most cases.

Based on a model given by Huckins et al. [15] and the environmental conditions at test sites, the time required for reaching $90 \%$ of equilibrium concentration is estimated to be about $14 \mathrm{~d}$ for phenanthrene $\left(\log K_{\mathrm{ow}}=4.5\right)$. However, $2,2^{\prime}, 5,5^{\prime}$-tetrachlorobiphenyl $\left(\log K_{\text {ow }}=5.6-6.1\right)$ would attain only $75 \%$ of the equilibrium concentration after our $28-\mathrm{d}$ exposure. These calculations are based on the assumption that the uptake rates measured during low-flow calibrations $(<1$ $\mathrm{cm} / \mathrm{s}$ ) $[15,18]$ increase by 12 -fold at the high flows observed in this study $(100 \mathrm{~cm} / \mathrm{s})$. This assumption seems reasonable because Booij et al. [18] have shown that an increase in flow velocity from $<1 \mathrm{~cm} / \mathrm{s}$ to $30 \mathrm{~cm} / \mathrm{s}$ results in a fourfold rise in the sampling rate of aqueous diffusion layer controlled chemicals (those with $K_{\text {ow }}$ s $>4.5$ ). The deployment devices also did not appear to significantly reduce flow/turbulence.

Tables 1 to 3 show the normalized concentrations of target HOCs in fish lipid and sediment organic carbon. Nearly all the HOCs found in fish and sediment were detected in trioleinSPMDs. The only exception was chlorophenols in fish and sediments at the Xinyang city site. However, these compounds were detected in SPMDs at the Huainan site. The $\mathrm{pH}$ of the water greatly affects the fractional amount of chlorophenols that is available (the amount of neutral species) for SPMD uptake. Clearly, SPMDs do not sample ionic species, whereas 
Table 2. Normalized concentration of PCB congeners in fish, sediment, and semipermeable membrane devices (SPMD)

\begin{tabular}{|c|c|c|c|c|c|c|}
\hline \multirow[b]{2}{*}{ Congeners } & \multicolumn{2}{|c|}{$\begin{array}{c}\text { Fish } \\
(\mu \mathrm{g} / \mathrm{kg} \text { lipid })\end{array}$} & \multicolumn{2}{|c|}{$\begin{array}{c}\text { Sediment } \\
(\mu \mathrm{g} / \mathrm{kg} \text { organic carbon })\end{array}$} & \multicolumn{2}{|c|}{$\begin{array}{c}\text { SPMD } \\
(\mu \mathrm{g} / \mathrm{kg} \text { triolein })\end{array}$} \\
\hline & Xinyang ${ }^{\mathrm{a}}$ & Huainan $^{\mathrm{a}}$ & Xinyang & Huainan & Xinyang & Huainan \\
\hline 5 & 0.03 & 0.10 & $0.20 \pm 0.05$ & $0.04 \pm 0.01$ & $0.17 \pm 0.07$ & $0.13 \pm 0.08$ \\
\hline 16 & 0.50 & 1.38 & $1.77 \pm 0.08$ & $0.60 \pm 0.07$ & $1.42 \pm 0.54$ & $1.98 \pm 1.60$ \\
\hline 18 & 0.16 & 0.13 & $0.33 \pm 0.12$ & $0.22 \pm 0.01$ & $0.40 \pm 0.21$ & $0.26 \pm 0.10$ \\
\hline 20 & 1.33 & 1.96 & $2.53 \pm 0.11$ & $3.41 \pm 1.01$ & $5.67 \pm 2.95$ & $6.48 \pm 3.56$ \\
\hline 26 & 0.16 & 0.41 & $0.26 \pm 0.01$ & $0.36 \pm 0.11$ & $0.67 \pm 0.64$ & $0.51 \pm 0.18$ \\
\hline 28 & 0.16 & 0.26 & $1.67 \pm 0.29$ & $0.84 \pm 0.34$ & $5.97 \pm 5.06$ & $1.28 \pm 1.00$ \\
\hline 31 & 0.02 & 0.03 & $0.03 \pm 0.001$ & $0.02 \pm 0.003$ & $0.14 \pm 0.11$ & $0.08 \pm 0.03$ \\
\hline 37 & 4.66 & 14.0 & $18.0 \pm 6.80$ & $12.2 \pm 3.60$ & $14.5 \pm 5.50$ & $14.0 \pm 5.50$ \\
\hline 40 & 4.18 & 5.71 & $7.30 \pm 0.32$ & $5.00 \pm 8.77$ & $5.20 \pm 4.60$ & $13.4 \pm 5.17$ \\
\hline 41 & 3.67 & 5.59 & $14.4 \pm 0.63$ & $14.5 \pm 6.28$ & $25.0 \pm 11.0$ & $16.1 \pm 4.38$ \\
\hline 42 & 0.65 & 0.56 & $0.72 \pm 0.03$ & $0.49 \pm 0.06$ & $1.85 \pm 0.72$ & $1.62 \pm 0.84$ \\
\hline 52 & 0.50 & 0.82 & $3.10 \pm 1.51$ & $0.71 \pm 0.08$ & $1.67 \pm 0.62$ & $1.67 \pm 0.62$ \\
\hline 62 & 0.22 & 4.90 & $6.30 \pm 0.27$ & $8.50 \pm 2.53$ & $24.0 \pm 6.27$ & $20.3 \pm 13.3$ \\
\hline 66 & 1.67 & 2.50 & $3.20 \pm 0.14$ & $2.20 \pm 0.25$ & $9.30 \pm 4.95$ & $5.16 \pm 1.96$ \\
\hline 69 & 0.01 & 0.28 & $0.72 \pm 0.27$ & $0.49 \pm 0.14$ & $1.27 \pm 0.75$ & $0.58 \pm 0.22$ \\
\hline 70 & 0.64 & 2.22 & $0.56 \pm 0.74$ & $0.78 \pm 0.09$ & $2.57 \pm 0.90$ & $0.91 \pm 0.36$ \\
\hline 74 & 0.52 & 1.91 & $0.82 \pm 0.04$ & $0.55 \pm 0.06$ & $1.05 \pm 0.03$ & $1.58 \pm 0.58$ \\
\hline $101(77)$ & 11.5 & 4.67 & $6.00 \pm 3.74$ & $4.05 \pm 0.48$ & $13.5 \pm 7.03$ & $17.4 \pm 7.03$ \\
\hline 84 & 6.12 & 4.85 & $18.7 \pm 9.10$ & $4.20 \pm 0.49$ & $16.0 \pm 10.8$ & $8.00 \pm 0.10$ \\
\hline 89 & 23.3 & 34.4 & $88.0 \pm 3.85$ & $60.0 \pm 7.00$ & $57.0 \pm 0.80$ & $99.5 \pm 51.7$ \\
\hline 90 & 17.3 & 98.7 & $95.1 \pm 25.2$ & $21.0 \pm 2.50$ & $122.1 \pm 130.0$ & $40.7 \pm 0.70$ \\
\hline
\end{tabular}

${ }^{\text {a China. }}$

fish and sediments are known to accumulate ionic organic species [12]. Table 2 shows that all PCB congeners measured in fish and sediment were detected in triolein-SPMDs. A number of HOCs (mostly PAHs) were not detected in our limited sampling of fish or sediments at certain sites but were detected in SPMDs (Table 3). This observation is consistent with the fact that fish metabolize PAHs and that the greatest portion of PAHs with low to moderate $K_{\mathrm{ow}}$ s will typically be in the dissolved phase [19].

Tables 1 to 3 show that differences in the normalized concentrations of HOCs in sediments, fish, and triolein-SPMDs (excluding nondetected analytes) are generally much less than an order of magnitude. In this very limited comparison, HOC concentrations in fish appear to be closely related to their concentrations in sediment (Tables 1 to 3 ). This observation suggests that the fish analyzed did not metabolize most of the HOC residues and that both matrices were exposed to similar sources of contaminants. Tables 1 to 3 also indicate that the equilibrium concentrations of HOCs in SPMD triolein may be higher than in the fish lipid at equilibrium. Fish extracts typically contain not only neutral triglycerides, such as triolein, but more polar lipids as well [20]. Thus, for HOCs the equilibrium partition coefficients would generally be expected to be lower for the fish lipid mixture than triolein, unless biomagnification occurs.

Clearly, a single sample from two sites is inadequate to draw any conclusion on the feasibility of predicting concentrations of certain chemicals in fish from triolein-SPMD levels. However, the numbers are encouraging. In the case of target compounds with moderate $\log K_{\mathrm{ow}} \mathrm{s}$, investigators can often derive water concentrations from SPMD levels and then compute BCFs from well-known $\log$ BCF $\sim \log K_{\text {ow }}$ relationships [21].

Figure 1 shows logarithmic plots of the logarithmic concentrations of HOCs in fish and in triolein-SPMDs at the two sampling sites. The regression equations derived from the con-

Table 3. Normalized concentrations of polycyclic aromatic hydrocarbons in fish, sediment, and semipermeable membrane devices (SPMD)

\begin{tabular}{|c|c|c|c|c|c|c|}
\hline \multirow[b]{2}{*}{ Compounds } & \multicolumn{2}{|c|}{$\begin{array}{c}\text { Fish } \\
(\mathrm{mg} / \mathrm{kg} \text { lipid })\end{array}$} & \multicolumn{2}{|c|}{$\begin{array}{c}\text { Sediment } \\
(\mathrm{mg} / \mathrm{kg} \text { organic carbon) }\end{array}$} & \multicolumn{2}{|c|}{$\begin{array}{c}\text { SPMD } \\
(\mathrm{mg} / \mathrm{kg} \text { triolein })\end{array}$} \\
\hline & Xinyang ${ }^{a}$ & Huainan $^{\mathrm{a}}$ & Xinyang & Huainan & Xinyang & Huainan \\
\hline Naphthalene & 0.35 & 0.55 & $0.56 \pm 0.07$ & $0.71 \pm 0.25$ & $2.39 \pm 0.11$ & $2.65 \pm 0.43$ \\
\hline Acenaphthene & 0.56 & 0.41 & $0.20 \pm 0.03$ & $0.22 \pm 0.01$ & $1.47 \pm 0.11$ & $1.59 \pm 0.23$ \\
\hline Fluorene & 0.33 & 0.87 & $0.69 \pm 0.21$ & $0.53 \pm 0.14$ & $1.93 \pm 0.22$ & $2.05 \pm 0.29$ \\
\hline Fluoranthene & 0.70 & 0.68 & $\mathrm{ND}^{\mathrm{b}}$ & ND & $2.20 \pm 0.15$ & $1.27 \pm 0.19$ \\
\hline Phenanthrene & 0.88 & 1.40 & $0.92 \pm 0.29$ & $1.29 \pm 0.26$ & $4.16 \pm 0.17$ & $3.59 \pm 0.44$ \\
\hline Anthracene & 1.02 & ND & $1.15 \pm 0.29$ & $0.31 \pm 0.06$ & $4.53 \pm 0.25$ & $2.53 \pm 0.38$ \\
\hline Pyrene & 0.59 & 0.94 & $0.30 \pm 0.40$ & $1.53 \pm 0.20$ & $2.17 \pm 0.19$ & $1.22 \pm 0.40$ \\
\hline Benz $[a]$ anthracene (+Chrysene) & 1.97 & 2.48 & $0.95 \pm 0.72$ & $2.17 \pm 0.80$ & $1.60 \pm 0.12$ & $3.23 \pm 0.26$ \\
\hline Benzo $[b]$ fluoranthene & 0.39 & 0.65 & $0.69 \pm 0.17$ & $0.73 \pm 0.29$ & $6.27 \pm 0.29$ & $3.04 \pm 0.27$ \\
\hline Benzo[k]fluoranthene & ND & 0.31 & $0.30 \pm 0.05$ & $0.33 \pm 0.02$ & $3.65 \pm 0.17$ & $1.76 \pm 0.37$ \\
\hline Benzo $[a]$ pyrene & 0.86 & 0.99 & $0.92 \pm 0.16$ & $1.02 \pm 0.25$ & $2.80 \pm 0.16$ & $2.46 \pm 0.53$ \\
\hline Dibenzo $[a, h]$ anthracene & 0.80 & 0.82 & $1.02 \pm 0.33$ & $0.89 \pm 0.21$ & $6.32 \pm 0.13$ & $1.71 \pm 0.20$ \\
\hline
\end{tabular}

a China.

${ }^{\mathrm{b}} \mathrm{ND}=$ did not exceed detection limit. 

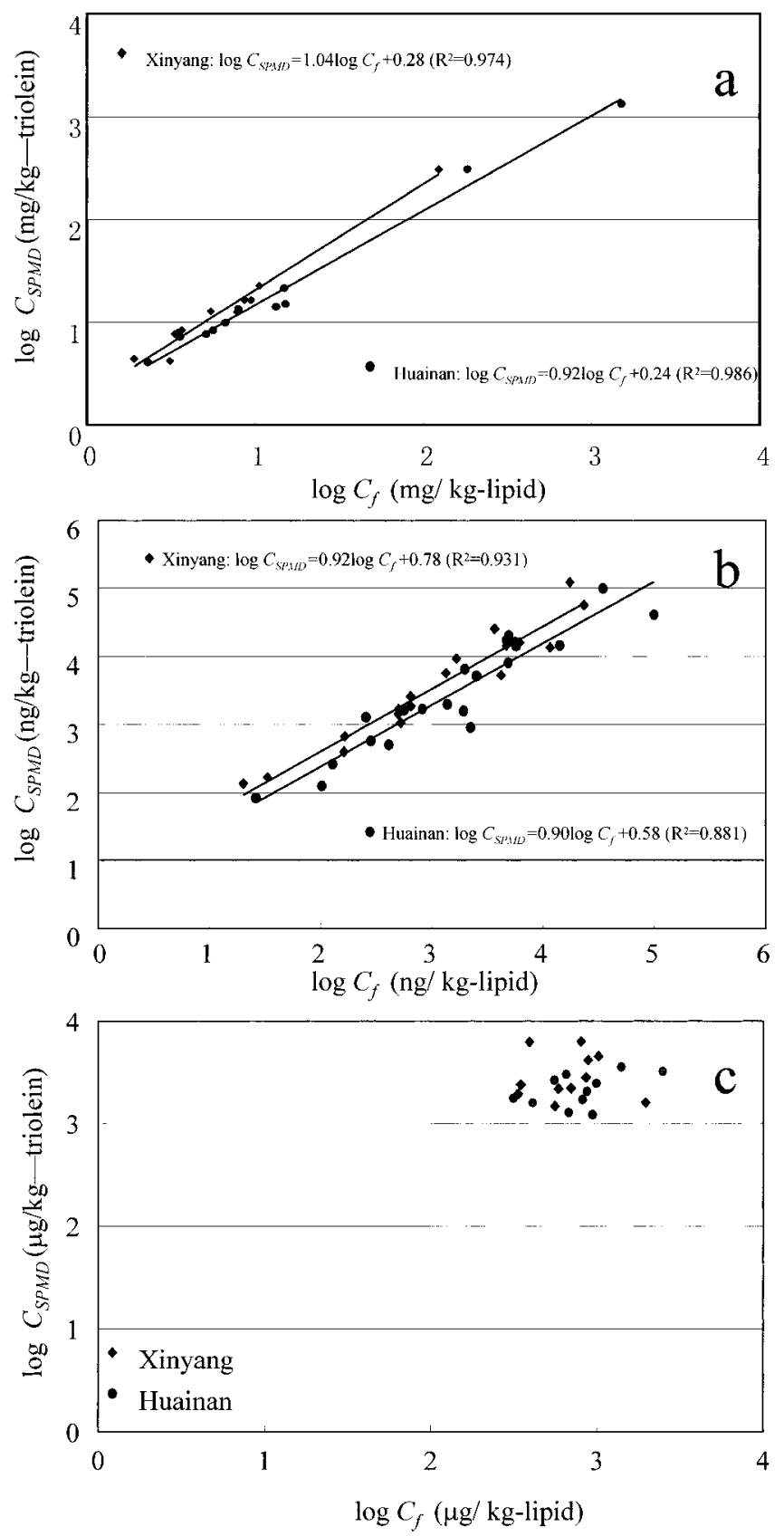

Fig. 1. Regression analysis plots of the logarithmic concentrations of target contaminants in fish lipid and in triolein-semipermeable membrane devices (SPMD) (a) for substituted benzenes and pesticides, (b) for polychlorinated biphenyls, and (c) for polycyclic aromatic hydrocarbons. (The lipid contents for grass carp caught at Xinyang and Huainan, China, were 6.1 and $3.9 \%$, respectively.)

centrations of substituted benzenes and pesticides (Fig. 1a) in fish and triolein-SPMD at the Xinyang $\left(R^{2}=0.974\right.$, slope $=$ $1.04)$ and Huainan $\left(R^{2}=0.986\right.$, slope $\left.=0.92\right)$ sites were very similar, and the slopes of the regression equations were close to unity. Regression analysis of logarithmic PCB concentrations in fish and in triolein-SPMDs at Xinyang $\left(R^{2}=0.931\right.$, slope $=0.92)$ and Huainan $\left(R^{2}=0.881\right.$, slope $\left.=0.90\right)$ sites gave similar equations (Fig. 1b), and again the slopes of the regression lines were close to unity. The intercepts of the PCB plots were 0.78 and 0.58 , respectively. However, no correlation was found between the logarithmic concentrations of different PAHs in fish and in triolein-SPMDs at the two sites (Fig. 1c).
This finding could be due to the small sample size or because fish are known to metabolize PAHs. Regardless, the concentrations of selected PAHs in fish and triolein-SPMDs were within one order of magnitude. It is well known that no biological degradation occurs in triolein SPMDs; however, the rates of biodegradation/biotransformations for PAHs accumulated in fish depends on their structures. The correlation is appropriate only in the absence of biodegradation/biotransformations.

Other investigators have found good correlations between the accumulation of chemicals in triolein-SPMDs and caged mussels (Mytilus edulis), with $R^{2}$ values ranging from 0.57 to 0.85 for individual pesticides and from 0.81 to 0.96 for individual congeners of PCBs [10]. In the present limited comparison, the observed $R^{2}$ values range from 0.974 to 0.986 for individual substituted benzenes and pesticides $(n=14)$ and from 0.881 to 0.931 for individual congeners of PCBs $(n=$ 21).

The logarithm partitioning coefficients between trioleinSPMD $\left(\log K_{\mathrm{SPMD}}\right)$ is linearly proportional to $\log K_{\text {ow }}$, which is in part the basis of using the triolein-SPMD as a mimetic (mimics a biological process in simple media) sampling tool. Similarly, the equilibrium partitioning of a contaminant between fish and water $(\log \mathrm{BCF})$ can be related to the $\log K_{\mathrm{ow}}$ of a chemical by simple linear regression equations (log BCF $=A \log K_{\text {ow }}+B$ ) for HOCs with $\log K_{\text {ow }}$ s ranging from 2.0 to 6.0. Several studies have shown that the slope of linear regression is approximately $1[6,20]$. A simple relationship of $\log K_{\mathrm{tw}}=\log K_{\mathrm{ow}}+0.105$ was derived by Chiou [22], in which $K_{\mathrm{tw}}$ is the partitioning coefficient of a contaminant between triolein and water, and Gale [23] has indicated that the $K_{\text {SPMD }}$ is $0.1 \sim 0.5 \times K_{\mathrm{tw}}$. The combination of these relationships resulted in the following equation:

$$
\begin{aligned}
\log \mathrm{BCF} & =A \log K_{\mathrm{SPMD}}+B \text { or } \\
\log C_{\mathrm{SPMD}} & =\alpha \log C_{\mathrm{f}}+\beta
\end{aligned}
$$

where $\beta$ integrates constants in these expressions. Equation 1 can be used to predict the BCF of feral fish by measuring the equilibrium concentration of an $\mathrm{HOC}$ in deployed trioleinSPMDs and by subtracting the logarithmic concentration of its bioavailable water residues. The verification of the linearity of Equation 1 is actually the verification of the linear relationship between $\log K_{\text {SPMD }}$ and $\log$ BCF. Clearly, larger sample sets are needed to test the usefulness of the model.

The equilibrium partitioning of a contaminant between sediment organic carbon and water $\left(\log K_{\mathrm{oc}}\right)$ can be related to the $\log K_{\text {ow }}$ by simple linear regression equations $\left(\log \mathrm{BCF}=A^{\prime}\right.$ $\log K_{\text {ow }}+B^{\prime}$ ). Using the same approach as for biota, regression analysis of sediment and triolein-SPMD data gave the following expression:

$$
\begin{aligned}
\log K_{\mathrm{oc}} & =A \log K_{\mathrm{SPMD}}+\gamma \text { or } \\
\log C_{\mathrm{SPMD}} & =\chi \log C_{\mathrm{oc}}+\lambda
\end{aligned}
$$

where $C_{\mathrm{oc}}$ is the analyte concentration in sediment organic carbon. Again, the $\log K_{\text {SPMD }}$ can be used to predict $\log K_{o c}$ only when equilibrium between the sediment organic carbon and the triolein-SPMD is achieved.

Figure 2 shows logarithmic plots of substituted benzenes, pesticides, PCBs, and PAHs in triolein-SPMDs and sediment organic carbon at the two study sites along the Huaihe River. The slopes of the regressions for substituted benzenes (Fig. 2a) and for PCBs (Fig. 2b) were quite similar, and the same 

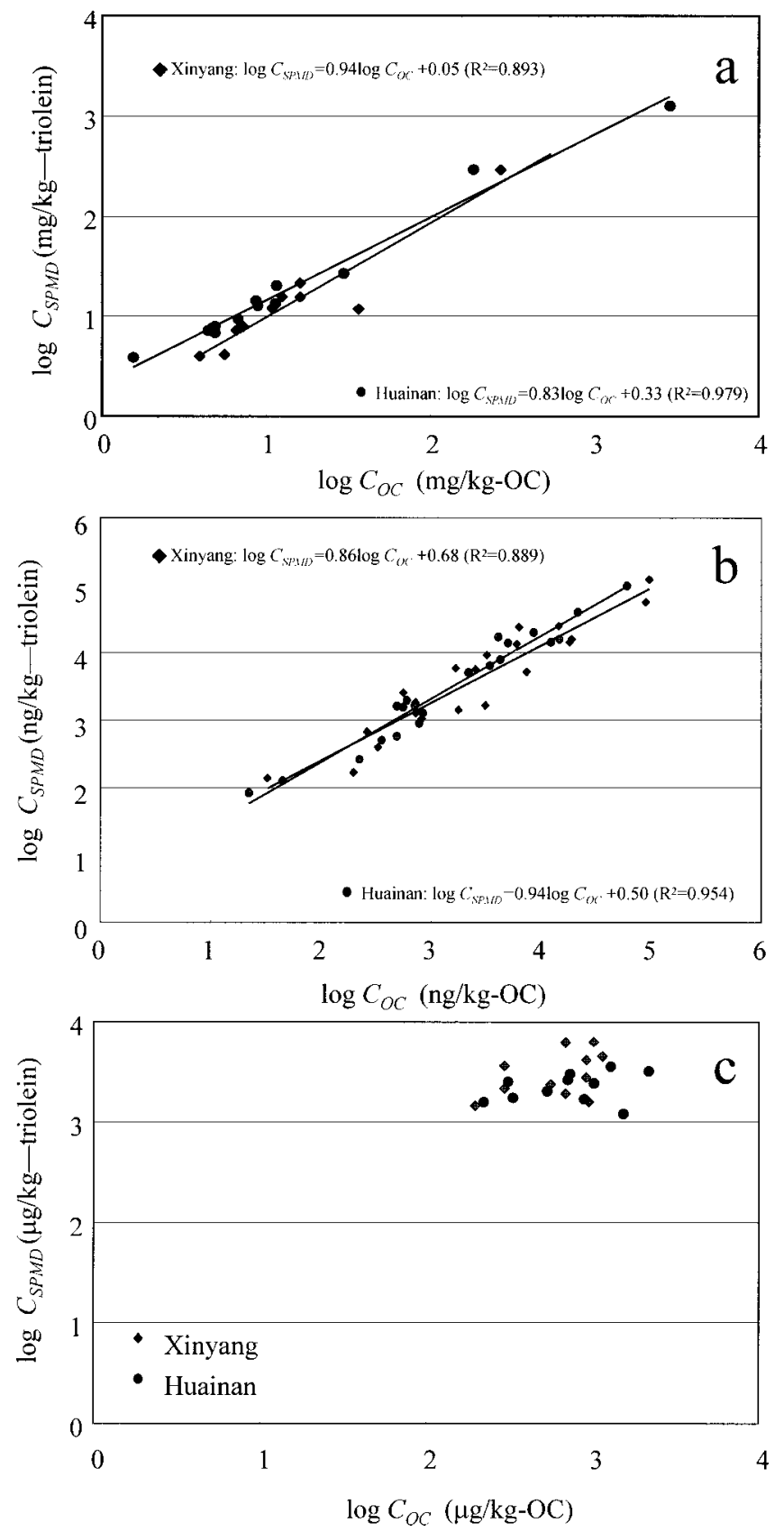

Fig. 2. Regression analysis plots of the logarithmic concentrations of target contaminants in sediment organic carbon and in triolein-semipermeable membrane devices (SPMD) (a) for substituted benzenes and pesticides, (b) for polychlorinated biphenyls, and (c) for polycyclic aromatic hydrocarbons. (The organic carbon contents of sediments from Xinyang and Huainan, China, were 3.25 and $4.51 \%$, respectively.) $\mathrm{OC}=$ organic carbon.

line almost fits both data sets. Thus, for this very limited set of data and exposure conditions, it appears that triolein-SPMDs are predictive of the bioavailabilities of selected sedimentassociated contaminants.

As observed for biota, no correlation appeared to exist between the logarithmic concentrations of PAHs in sediment and in triolein-SPMDs (Fig. 2c). Additional sampling is required to confirm this observation.

The land use and industries at the two sample sites along the Huahe River are quite similar. The two study sites are almost $400 \mathrm{~km}$ apart. Concentrations of most target compounds in samples from Huainan appeared to be higher than those from Xinyang (Tables 1 to 3 ). However, the slopes and regression coefficients obtained from correlation (excluding PAHs) were quite similar. This finding may indicate that at the two sample sites, the dissolved phase dominates the transport of these contaminants and that steady-state conditions existed among biota, suspended sediments, and water phases.

From these findings and related discussions, it appears that triolein-SPMDs have significant potential as surrogates for biomonitoring organisms and sediments, at least for moderate to low $K_{\text {ow }}$ s contaminants and when exposed in high-flow/turbulent environments. Although SPMDs were designed for moderate to high $K_{\text {ow }}$ compounds, this work and earlier work $[16,17]$ show that they are quite effective accumulators of relatively low $K_{\text {ow }}$ compounds, such as certain chlorophenols and nitroaromatics. In addition, in this limited sampling, SPMD concentrations appear to parallel fish concentrations of these compounds. Finally, the utility of SPMDs is underscored by the relative simplicity of their field applications and the potential for standardization.

Acknowledgement-This work was supported by the Chinese Academy of Science (KZCX2-410) and the China Natural Science Foundation (2977024).

\section{REFERENCES}

1. Karickhoff SW, Brown DS, Scott TA. 1979. Sorption of hydrophobic pollutants on natural river sediment. Water Res 13:241248.

2. Adriaanse M, Niederlander HG, Stortelder PBM. 1995. Monitoring Water Quality in the Future: Chemical Monitoring. Ministry of Housing, Spatial Planning and the Environment, The Hague, The Netherlands.

3. Veith G, Dedoe D, Bergstedt B. 1979. Measuring and estimating the bioconcentration factor of chemicals in fish. J Fish Res Board Can 36:1040-1048.

4. Geyer H, Sheehan P, Kotzias D. 1982. Prediction of ecotoxicological behavior of chemicals: Relationship between physicochemical properties and bioaccumulation of organic chemicals in the mussel Mytilus edulis. Chemosphere 11:1121-1134.

5. Uhle ME, Chin YP, Aiken GR, Mcknight DM. 1999. Binding of polychlorinated biphenyls to aquatic humic substances: The role of subtract and sorbate properties on partitioning. Environ Sci Technol 33:2715-2718.

6. Di Toro DM, Zarba CS, Hansen DJ, Berry WJ, Swartz RC, Cowan CE, Pavlou SP, Allen HE, Thomas NA, Paquin PR. 1991. Technical basis for establishing sediment quality criteria for nonionic organic chemicals using equilibrium partitioning. Environ Toxicol Chem 10:1541-1583.

7. Gale R, Huckins JN, Petty J, Peterman P, Williams L. 1997. Comparison of the uptake of dioxin-like compounds by caged channel catfish and semipermeable membrane devices in the Saginaw River, Michigan. Environ Sci Technol 31:178-187.

8. Huckins JN, Petty JD, Lebo JA, Orazio CE, Prest HF, Tillitt DE, Ellis GS, Johnson BT, Manuweera GK. 1996. Semipermeable membrane devices (SPMDs) for the concentration and assessment of bioavailable organic contaminants in aquatic environments. In Ostrander GK, ed, Techniques in Aquatic Toxicology. Lewis, Boca Raton, FL, USA, pp 625-655.

9. Huckins JN, Tubergen MW, Manuweera GK. 1990. Semipermeable membrane devices containing model lipid: A new approach to monitoring the bioavailability of lipophilic contaminants and estimating their bioconcentration potential. Chemosphere 20:533-552.

10. Hofelt CS, Shea D. 1997. Accumulation of organochlorine pesticides and PCBs by semipermeable membrane devices and $M y-$ tilus edulis in New Bedford Harbor. Environ Sci Technol 31: 154-159.

11. Petty JD, Huckins JN, Zajicek JL. 1993. Application of semipermeable membrane devices (SPMDs) as passive air samplers. Chemosphere 27:1609-1624.

12. Prest HF, Huckins JN, Petty JD, Herve S, Paasivirta J, Heinonen 
P. 1995. A survey of recent results in passive sampling of water and air by semipermeable membrane devices. Mar Pollut Bull 31:306-312.

13. Lebo J, Zajicek J, Huckins JN, Petty J, Peterman P. 1992. Use of semipermeable membrane devices for in situ monitoring of polycyclic aromatic hydrocarbons in aquatic environments. Chemosphere 25:697-718.

14. Wang Y, Wang Z, Liu J, Ma M, Belzile N. 1999. Monitoring priority pollutants in the Yanghe river by dichloromethane extraction and semipermeable membrane device (SPMD). Chemosphere 39:113-131.

15. Huckins JN, Petty JD, Prest HF, Clark RC, Alvarez DA, Orazio CE, Lebo JA, Cranor WL, Johnson BT. 2001. A guide for the use of semipermeable membrane devises (SPMDs) as samplers of waterborne hydrophobic organic contaminants. API Publication 4690. American Petroleum Institute, Washington DC.

16. Wang Y, Wang Z, Wang C. 1998. Uptake of moderately hydrophobic chlorophenols from water by semipermeable membrane devices (SPMDs) and by fish (Cassius auratus). Chemosphere 37:327-339.

17. Wang Y, Wang Z, Wang C, Wang W. 1998. Uptake of weakly hydrophobic nitroaromatics from water by semipermeable membrane devices (SPMDs) and by fish (Cassius auratus). Chemosphere 38:51-66.

18. Booij K, Sleiderink HM, Smedes F. 1998. Calibrating the uptake kinetics of semipermeable membrane devices using exposure standards. Environ Toxicol Chem 17:1236-1245.

19. Connell DW. 1989. Bioaccumulation of Xenobiotic Compounds. CRC, Boca Raton, FL, USA.

20. Schneider R. 1982. Polychlorinated biphenyls (PCBs) in cod tis sues from the Western Baltic: Significance of equilibrium partitioning and lipid composition in the bioaccumulation of lipophilic pollutants in gill-breathing animals. Meeresforschung 29:69-70.

21. Verhaar HJM, Jongh JJ, Hermens JM. 1999. Modeling the bioconcentration of organic compounds by fish: A novel approach. Environ Sci Technol 33:4069-4072.

22. Chiou C. 1985. Partitioning coefficients of organic compounds in lipid-water systems and correlations with fish bioconcentration factors. Environ Sci Technol 19:57-62.

23. Gale RW. 1998. Three-compartment model for contaminant accumulation by semipermeable membrane devices. Environ Sci Technol 32:2292-2300. 